\title{
General and specialized Orthopaedics
}

\author{
Marius M. Scarlat ${ }^{1}$
}

Published online: 10 April 2019

(C) SICOT aisbl 2019

The twenty-first Century changed our way of communication and also our way of reading and publishing science. Since Gutenberg our method of learning was associated with reading printed material and the "traditional" way of being a scholar was associated with attending lectures made by teachers "Ex cathedra" where knowledge was almost dogmatic and unquestionable. Universities were in charge of sharing the science. The practice of surgery was taught in the "operating theatre" where technical manoeuvres were demonstrated by well-dressed attendings that eventually washed their hands after the case. A majority of surgical cases were amputations. [1] Museums and libraries are depositories of the efforts made over centuries to provide healing and hope, keeping medical evidence and sharing our knowledge with the upcoming generations. Medical Journals appeared in the eighteenth century and became rapidly peer-reviewed, this major step opening the way to criticism, doubt, questions and progress.

With the Internet and electronic communication our traditions were challenged and new tools were developed. Patient databases became more reliable and easier to understand, medical statistics and meta-analysis became possible. A plethora of medical Journals appeared and competition between publications raised based on the visibility, readership and citations. This drive is associated with inherent growth in new publications that have short life span and have an aggressive behaviour [2] New values were based on the ability of a new publication to impact, change or improve current practice. When a paper is published in our days, the data, text, images and full information are available instantly everywhere. In this acceleration of publications, augmentation of volume is not synonymous with augmentation

Marius M. Scarlat

mscarlat@gmail.com

1 Clinique Chirurgicale St Michel, Groupe ELSAN, Toulon, France in quality and many papers are just published and barely or never cited. [3] Bibliometric studies are evaluating the tendencies based on different factors, including specialties. [4, 5] Results may depend on conflicts of interest and funding $[6,7]$.

General Orthopaedics appeared as a specialty in the eighteenth century, divided in a high number of subspecialties in the twentieth century and keeps expanding. Medical specialties became broader in terms of field of expertise and more accurate in terms of communicated results. Borderline fields of expertise like "nutrition for patients with chronic wounds" or "joint reaction to specific immune triggers" became new directions of research within subspecialties. "International Orthopaedics" published regularly special issues dedicated to broad fields of expertise such as "Discal disease" [8].

Each journal issue should provide valuable lecture for the readers. Composing a Journal Issue is a delicate task involving the board and the Editors who want to provide the best mix between modern and traditional orthopaedics including new facts of science, traditions, protocols, treatments validation and recent basic science research. This usually results in a panel of papers carefully chosen from over 2500 submitted manuscripts per year with a rejection rate that is terribly high. Our aim is to compose the Journal according to the trends matching the current practice and research; however we know that the access to science is not even on our planet. We acknowledge in the general orthopaedics section efforts made by developing economies to provide quality orthopaedics in specific geographic locations and this stirs debate and comments $[9,10]$. We provide literature on general emergency principles, war and life threatening injuries $[11,12]$.

One important general health issue is the quality of Bone and joints that impacts the quality of the movement and freedom of move is as important as the freedom of speech in a modern world where the patients and potential patients are always comparing themselves with "normal people" and where everybody wants to be "normal". [13] 
Orthopaedic Surgery became specialized and this trend is exponential, more new fields and competencies are opening, we have shoulder specialists, knee specialists, hand, upper limb, ankle, forefoot and ankle experts, neurologic and orthopaedic spine centres and now even more specialized arthroscopy and minimally invasive dedicated units with "open surgery" as an option. Colleagues who perform mainly knee arthroplasty work in centres where others are doing only knee arthroscopic reconstruction can tell you more about that. Will this trend continue or will this stop at some point? Are we facing new changes with robotics and technology progress or will biology with genetics and molecular chemistry prevail in the race for better orthopaedics? [14, 15] .. Good and reliable natural or artificial joints, strong bones and excellent muscular condition are a part of our concerns. Patients became more demanding and there is a continuous effort to provide new implants and devices that enhance life quality and locomotion for all age groups.

The general orthopaedic surgeon acting like a local "guru" who fifty years ago was performing hip fractures fixation, elbow release and ankle arthrodesis was replaced by three specialists working in the same centre. The number of patients multiplied by three as well, result of a longer lifespan and of a higher demand for quality in locomotion.

Speaking about technology and novelty with a journalist I learned that currently three years-old use tablets and computers to play, however, this is a new model as the toddler was learning two-centuries ago how to catch a chicken or how to use a lasso. There were different methods of learning and we should probably acknowledge both individuals, as we acknowledge today the third year resident who is able to perform arthroscopic knots as compared to his ancestor who was learning to amputate fast and without anesthesia.

The number of papers dedicated to general orthopaedics is quite stable over several years and we publish between three and five general orthopaedics articles in each issue. Many of those papers are describing treatment for general conditions like growth pathologies, arthritis or infection. Some papers describe or analyze conditions that have to be recognized by surgeons worldwide such as genetic or paediatric conditions or predictive factors for management emergency of elderly; there are also papers related to the use of analgesia and some techniques for real for pain relief that can be managed by the general orthopaedic doctor. [16-19]

Our readers are asking for better performance for higher ranking and for higher impact factor. Our Board and correspondents advise to keep the balance between general orthopaedics papers that a tendency to be less cited and the more specialized papers that include recent research. Paradoxically general orthopaedic papers are much downloaded and read.
We shall continue to publish papers in different specialties and papers of general basic orthopedics because our readership is heterogeneous and our mission of service is oriented to them.

\section{References}

1. Markatos K, Karamanou M, Saranteas T, Mavrogenis AF (2019) Hallmarks of amputation surgery. Int Orthop 43(2):493-499. https://doi.org/10.1007/s00264-018-4024-6

2. Rupp M, Anastasopoulou L, Wintermeyer E, Malhaan D, El Khassawna T, Heiss C (2019) Predatory journals: a major threat in orthopaedic research. Int Orthop. 2018 . Oct 4. https://doi.org/10. 1007/s00264-018-4179-1

3. Mavrogenis AF, Quaile A, Pećina M, Scarlat MM (2018) Citations, non-citations and visibility of international Orthopaedics in 2017. Int Orthop 42(11):2499-2505. https://doi.org/10.1007/s00264-0184198-y

4. Said HG, El-Radi MA, Hassanein MY, Said GZ (2018) Orthopaedic publications from Egypt in the last five years: a bibliometric report. Int Orthop 42(11):2507-2511. https://doi.org/ 10.1007/s00264-018-4152-z

5. Sun J, Guo Y, Scarlat MM, Lv G, Yang XG, Hu YC (2018) Bibliometric study of the orthopaedic publications from China. Int Orthop 42(3):461-468. https://doi.org/10.1007/s00264-0183828-8

6. Goldberg BA, Scarlat MM (2017) No free lunch in orthopedics. Int Orthop 41(10):1963-1964. https://doi.org/10.1007/s00264-0173642-8

7. Cavinatto L, Bronson MJ, Chen DD, Moucha CS (2018) Roboticassisted versus standard unicompartmental knee arthroplastyevaluation of manuscript conflict of interests, funding, scientific quality and bibliometrics. Int Orthop. https://doi.org/10.1007/ s00264-018-4175-5

8. Benzakour T, Igoumenou V, Mavrogenis AF, Benzakour A (2019) Current concepts for lumbar disc herniation. Int Orthop 43(4):841851. https://doi.org/10.1007/s00264-018-4247-6

9. George A, Ofori-Atta P (2019) Joint replacement surgery in Ghana (West Africa)-an observational study. Int Orthop. https://doi.org/10. 1007/s00264-019-04286-1

10. Yan Z, Tang X, Chen X, Liu Z (2019) Joint replacement surgery in Ghana (West Africa). Int Orthop. https://doi.org/10.1007/s00264019-04321-1

11. Alhammoud A, Maaz B, Alhaneedi GA, Alnouri M (2019) External fixation for primary and definitive management of open long bone fractures: the Syrian war experience. Int Orthop. https://doi.org/10. 1007/s00264-019-04314-0

12. Fakhri RM, Herard P, Liswi MI, Boulart AL, Al Ani AMK (2019) Decision-making algorithm for sequential treatment of diaphyseal bone gaps in war-wounded patients in the Middle East. Int Orthop. https://doi.org/10.1007/s00264-019-04317-x

13. Schmitz P, Lüdeck S, Baumann F, Kretschmer R, Nerlich M, Kerschbaum M (2019) Patient-related quality of life after pelvic ring fractures in elderly. Int Orthop 43(2):261-267. https://doi. org/10.1007/s00264-018-4030-8

14. d'Amato M, Ensini A, Leardini A, Barbadoro P, Illuminati A, Belvedere C (2018) Conventional versus computer-assisted surgery in total knee arthroplasty: comparison at ten years follow-up. Int Orthop. https://doi.org/10.1007/s00264-018-4114-5

15. Dumic-Cule I, Peric M, Kucko L, Grgurevic L, Pecina M, Vukicevic S (2018) Bone morphogenetic proteins in fracture repair. Int Orthop 42(11):2619-2626. https://doi.org/10.1007/s00264$018-4153-y$ 
16. Medina SH, Nadarajah V, Jauregui JJ, Smuda MP, Foster M, Meredith SJ, Packer JD, Henn RF 3rd. (2019) Orthopaedic surgery patients who use recreational marijuana have less pre-operative pain. Int Orthop 43(2):283-292. https://doi.org/10.1007/s00264018-4101-x

17. Li X, Zhang Q, Dong J, Zhang G, Chai W, Chen J (2018) Impact of surgical case order on peri-operative outcomes for total joint arthroplasty. Int Orthop 42(10):2289-2294. https://doi.org/10. 1007/s00264-018-3835-9

18. Wang H, Zhou Y, Liu J, Ou L, Zhao Y, Han J, Xiang L (2018) Traumatic fractures as a result of motor vehicle collisions in chil- dren and adolescents. Int Orthop 42(3):625-630. https://doi.org/10. 1007/s00264-018-3777-2

19. Ebrad S, Severyns M, Benzakour A, Roze B, Derancourt C, Odri GA, Rouvillain JL (2018) Pyoderma gangrenosum after orthopaedic or traumatologic surgery: a systematic revue of the literature. Int Orthop 42(2):239-245. https://doi.org/10.1007/s00264-017-3672-2

Publisher's note Springer Nature remains neutral with regard to jurisdictional claims in published maps and institutional affiliations. 